\title{
Effectiveness of Continuous Passive Motion in Hemiarthroplasty of Hip
}

\author{
Authors
}

\section{Harne MS ${ }^{1}$, Dr Sunil V.Deshmukh ${ }^{2}$, Dr Khatri $S \mathbf{M}^{3}$}

${ }^{1}$ Research fellow, Bapurao Deshmukh College of Engineering, Sevagram, Wardha, Maharashtra India -442102

${ }^{2}$ Principal, Suresh Deshmukh College of Engineering, Selukate, Wardha Maharashtra India -442001

${ }^{3}$ Dean, Allied Health Sciences, Principal, Dr. APJ Abdul Kalam College of Physiotherapy, Pravara Institute of

Medical Sciences, Loni BK, Tal:Rahata, Dist: Ahmednagar, Maharashtra, India-413 736

\section{Abstract}

Background: Continuous passive motion (CPM) is often used in the early post-operative rehabilitation of patients after hip surgery.

Aim of this study was to evaluate the effectiveness of new CPM device after hemi arthroplasty in terms of clinical scores and functional recovery.

Materials \& Methods: A total of 26 patients undergoing hemiarthroplasty were assigned into two groups. The experimental group received continuous passive motion and conventional physiotherapy and control group received only conventional physiotherapy for seven days as tolerated.

Results: Average difference in active range of hip abduction was $25 \pm 5$ degrees and Oxford hip score difference was $5.7 \pm 3.5$ in control group that received conventional physiotherapy. On the other hand, average difference in active range of hip abduction was $40 \pm 10$ degrees and Oxford hip score difference was $8.8 \pm 3.6$ in experimental group that received an additional intervention in form of continuous passive motion. Conclusion: Continuous passive motion machine can be used as an adjunct to conventional physiotherapy after hemiarthroplasty.

Keywords: biomedical engineering, design, continuous passive motion, hip and hemiarthroplasty.

\section{Introduction}

Anatomically, the hip joint is one of the true balland-socket joints of the body. The hip socket is called the acetabulum and forms a deep cup that surrounds the ball of the upper thigh bone, known as the femoral head. The thick muscles of the buttock at the back and the thick muscles of the thigh in the front surround the hip. ${ }^{1,2,3,4}$ Hemiarthroplasty is an operation or surgical procedure done at hip. Hemi means half and arthroplasty means joint replacement. Hemi replacement involves only half of the replacement i.e. only the ball portion of the hip joint is replaced. $5,6,7$

Common indications for hemiarthroplasty are intracapsular fracture of head of femur, rheumatoid arthritis, Paget's disease, fracture secondary to malignancy or cancer etc. ${ }^{8}$ It is contraindicated in 
infection and very young patient. ${ }^{9}$ Some of the complications of this surgery are anesthesia complications, thrombophlebitis, infection, dislocation, loosening, continued pain etc. ${ }^{10}$

It is believed that postoperative physiotherapy and rehabilitation plays an important role in the functional recovery of the patients undergoing this surgery. ${ }^{11}$ Ideal physiotherapy treatment duration is usually around 30 minutes and is limited due to various factors like symptoms, number of patients, fatigue etc ${ }^{12}$ However, passive hip movements with the help of continuous passive motion device can be done with a device that work on electricity and is believed to be beneficial in these kinds of patients during early post operative rehabilitation of patients after hip surgery. ${ }^{13}$

Continuous passive motion (CPM) is widely used as part of rehabilitation following hip and knee surgeries and there is evidence that its use following hemiarthroplasty can lead to a reduction in both hospital stay and pain killer analgesic requirements and an increase in early range of motion. ${ }^{14}$ In many centers, the use of CPM machines is limited by the cost of the equipment and hence we designed a low cost new CPM device that can allow functional movement in an arc for hip movements specially abduction which is believed to be one of the key movements. ${ }^{15}$ So the objective of the present study was to evaluate the effectiveness of new CPM device after hemi arthroplasty in terms of clinical scores and functional recovery.

\section{Materials \& Methods}

The study design used was quasi experimental study that was carried out with local ethics committee approval, to assess the added value of new CPM device immediately after the hip surgery inform of hemiarthroplasty using function and mobility as the main outcomes.

Participants: Participants scheduled for unilateral hemiarthroplasty surgery between the period of 5 March 2017 to 30 Jan 2018 at a private orthopedic hospital located at Sangamner, Maharashtra, India422 608. Participants were considered eligible if they were willing to participate in the study, age below 70 years, unilateral hip problem, able to communicate, understand Marathi and Medical fitness. Participants were excluded if they had comorbidity influencing mobility like claudication, previous hip surgery, operated upon by minimally invasive surgery and general debility. ${ }^{16}$ Participants were allocated to either experimental group or control group on alternate basis with the help of physiotherapists on duty.

Interventions: The experimental group received continuous passive motion for 10 to 30 minutes twice daily as per the tolerance along with conventional physiotherapy in form of active and passive therapeutic exercises and controlled group received only conventional physiotherapy for seven days as tolerated. Outcome measures used for this study were assessment of range of motion with goniometer and Oxford hip score.

Equipment: This was designed by the principle investigator for this research purpose. It had sub components like carriage unit, support stand, track, motor and body plate with velcro straps as shown in figure1. Special feature included its ability to permit continuous passive movement in an arc that will allow abduction or outward movement from the midline of the body at hip joint in an arc. (Figure1)

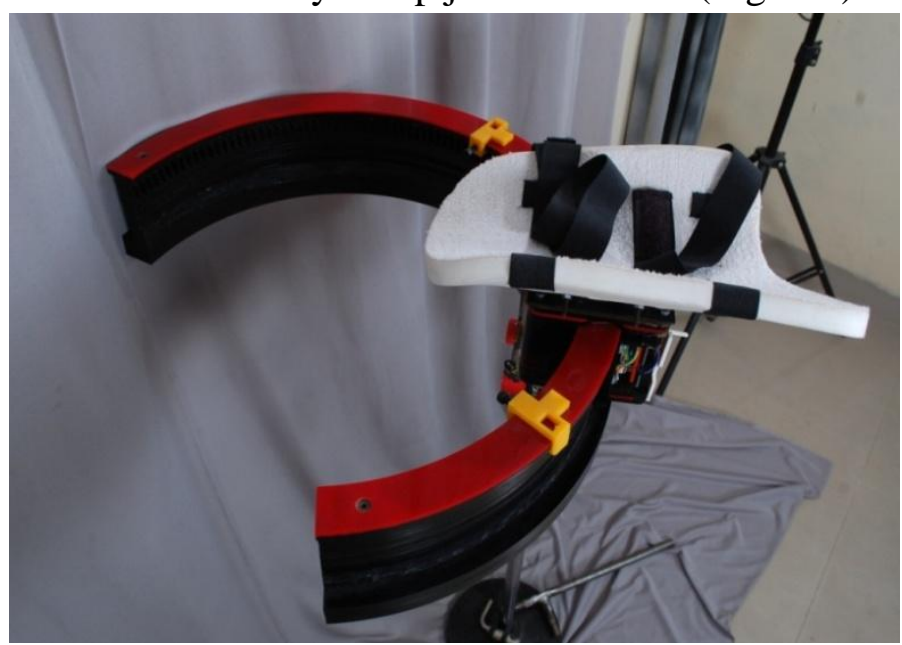

Figure 1: Continuous passive motion device used in the study 
Procedure: Before the surgery, participants were instructed about the conventional physiotherapy and the use of CPM device (experimental group only) so as to get acquainted and their baseline outcome measures were noted. Immediately after the surgery, when it was ensured the patient is stable, conventional physiotherapy and CPM or only conventional physiotherapy was started. All patients received a standardized conventional physiotherapy treatment program for almost 20 minutes and additional upto 30 minutes of CPM (in control group) use daily for two times as tolerated over the period of seven days. After the completion of seven days of interventions, once again the outcome measures were assessed for the further statistical analysis.

\section{Results}

A total of 28 participants undergoing hemiarthroplasty were screened for this study, of which 26 were eligible as per the inclusion criteria. Their demographics (table1) like the mean age of participants were65.31 \pm 4.6 . The average age of females was $64 \pm 4.6$ and for males was $65 \pm 3.5$. The gender ratio was $12: 14$. The mean body mass index of the participants was $28.5 \pm 3.1$. In participants treated with conventional physiotherapy (control group), pre intervention baseline values (table 2 and figure 2) were active range of hip abduction $5 \pm 5$ passive range of hip abduction $10 \pm 5.5$, Oxford hip score $30 \pm 6.8$ and post intervention scores were active range of hip abduction $30 \pm 5$ passive range of hip abduction40 \pm 5 , Oxford hip score 35.7 \pm 5.2.In participants treated with continuous passive motion and conventional physiotherapy (experimental group), pre intervention baseline values were active range of hip abduction $5 \pm 5$ passive range of hip abduction $10 \pm 5.5$, Oxford hip score $30 \pm 7.2$ and post intervention scores were active range of hip abduction $40 \pm 5$ passive range of hip abduction $45 \pm 5$, Oxford hip score. 38.8 \pm 3 .9. Thus the average difference in active range of hip abduction in control group was 25 and in experimental group it was 35. Statistical analysis with open Epi software showed a significant statistical difference with $\mathrm{t}=5.2915$, df 26 and $\mathrm{p}=0.00001560$. Oxford hip score difference in control group was $5.7 \pm 6.5$ and $8.8 \pm 5.6$ and this was statistically significant with $\mathrm{t}=2.00672, \mathrm{df}=26, \mathrm{p}=0.0336$.

Table 1: Demographics of participants

\begin{tabular}{|lc|}
\hline Parameter & Description \\
\hline Female participants & 12 \\
\hline Male participants & 14 \\
\hline Age & $65.31 \pm 4.6$ \\
\hline Left hip involvement & 12 \\
\hline Right hip involvement & 16 \\
\hline Body Mass Index & $28.5 \pm 3.1$ \\
\hline
\end{tabular}

Table 2: Outcome measures

\begin{tabular}{|lcc|} 
Parameter & $\begin{array}{c}\text { Control } \\
\text { Group }\end{array}$ & $\begin{array}{c}\text { Experimental } \\
\text { group }\end{array}$ \\
\hline PPROM Abduction on day 1 & $10 \pm 5.5$ & $10 \pm 5.5$ \\
\hline PROM Abduction after day 7 & $40 \pm 5$ & $40 \pm 5$ \\
\hline AROM Abduction on day 1 & $5 \pm 5$ & $5 \pm 5$ \\
\hline AROM Abduction after day 7 & $30 \pm 5$ & $40 \pm 5$ \\
\hline Oxford hip score on day 1 & $30 \pm 6.8$ & $30 \pm 7.2$ \\
\hline Oxford hip score on day 7 & $35.7 \pm 5.2$ & $38.8 \pm 3.9$ \\
\hline
\end{tabular}

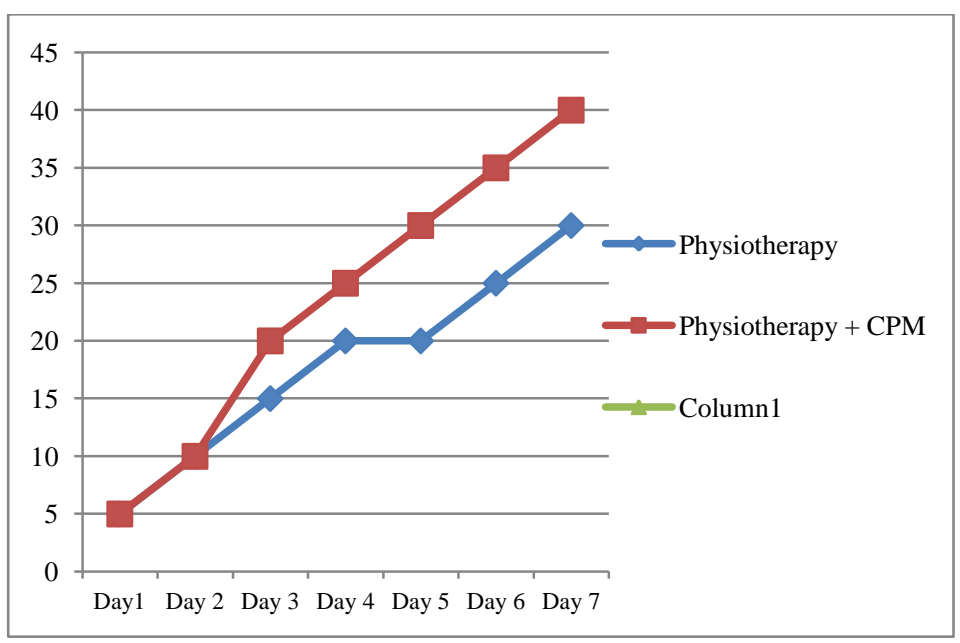

Figure 2: Active hip abduction range of motion

\section{Discussion}

Rehabilitation of hip after surgery like hemiarthroplasty is important since it helps the individual to get back to higher level of independence in terms of activities of daily living. 
Results of this study showed a significant difference in Oxford hip score, passive hip abduction and active hip abduction range of motion in participants who received continuous passive motion along with conventional physiotherapy as compared to only conventional physiotherapy. This could be due to various factors like, relief of pain, facilitation of movements, reduced spasm, enhanced nutrition, increased metabolic rate, stimulation of tissue remodeling, acceleration of tissue healing following surgery. ${ }^{17,18,19}$

Since there is hardly any study related that has investigated the effectiveness of CPM after hemiarthroplasty, it was difficult to interpret and compare our restuls with other investigators but we found that our results are similar to Basso DM ,Knapp L, Colwell CW, Morris BA and Coutts RD who studied the effectiveness of CPM in knee arthroplasty patients. $^{20,21,22}$

Some of the limitations of this study were small sample size, short duration of intervention, participants and investigators were not blinded to the interventions and we did not try to investigate the cause and effect relationship since it was thought to be beyond the scope of the current study. However, similar study can be done with randomization, use of different investigators for outcome assessments and interventions, larger sample size and longer intervention time.

\section{Conclusion}

New cost effective continuous passive motion device can be used as an adjunct to physiotherapy in the treatment of hemiarthroplasty to enhance active and passive range of hip abduction and activities of daily living.

\section{Acknowledgement}

We sincerely acknowledge the kind cooperation received from patients, doctors, physiotherapists, nurses and other support staff during this research period.

\section{References}

1. John Basmajian, Charles Slonecker: Grant's Method of Anatomy, 11th Ed, Lippincott Williams and Wilkinns, Baltimore, 2005.

2. Kadasne DK: Kadasne's text book of anatomy, Jaypee Brothers, New Delhi, 2009

3. Chaurasia BD: Human Anatomy - Regional and Applied: Volume I, Volume II and Volume III,4th Ed, CBS Publisher and Distributors, New Delhi,2010.

4. Standring Susan: Gray's Anatomy - The Anatomical Basis of Clinical Practice, 4th Ed, Elsevier Churchill Livingstone, London, 2005.

5. Varshney MK: Essential orthopedics principles and practice. Jaypeee Brothers, New Delhi, 2016.

6. Hurtling, D \& Kessler, R.M management of common musculoskeletal disorders physical therapy principals \& methods, 3 rd edition, JB Lippincott, Philadephia, 1996

7. Campbell's, operative orthopedics, 11th edition, Mosby Elsevier, 2008.

8. Onyemaechi, EG Anyanwu, EN Obikili and J Ekezie:Anatomical Basis for Surgical Approaches to the HipAnn Med Health Sci Res. 2014 Jul-Aug; 4(4): 487-494.

9. Magee, D.J: Orthopaedic physical assessment, 3rd edition, WB saunders, Philadelphia 1997.

10. Stanley Hoppenfield: Treatment and rehabilitation of fractures, 1stEd, Lippincott Wiliams \& Wilkins, USA,2000.

11. Minns Lowe CJ, Barker KL, Dewey ME, Sackley CM. Effectiveness of physiotherapy exercise following hip arthroplasty for osteoarthritis: a systematic review of clinical trials. BMC Musculoskelet Disord 2009; 10:98.

12. Barbay K. Research evidence for the use of preoperative exercise in patients preparing 
for total hip or total knee arthroplasty Orthop Nurs. 2009;28:127-33.

13. Salter RB, Simmonds DF, Malcolm BW, Rumble EJ, MacMichael D, Clements ND. The biological effect of continuous passive motion on the healing of full-thickness defects in articular cartilage.An experimental investigation in the rabbit. $\mathbf{J}$ Bone Joint Surg Am. 1980;62:1232-1251.

14. Wilk M, Franczuk B. Evaluating changes in the range of movement in the hip joint in patients with degenerative changes, before and after total hip replacement. Ortop Traumatol Rehabil. 2004; 6:342-349.

15. Salter RB, Hamilton HW, Wedge JH, Tile M, Torode IP, O'Driscoll SW, Murnaghan JJ, Saringer JH. Clinical application of basic research on continuous passive motion for disorders and injuries of synovial joints: a preliminary report of a feasibility study. $\mathbf{J}$ Orthop Res. 1984;1:325-342.

16. Bohannon RW: Clinical applications of continuous passive motion. Postgrad Adv Phys Ther 3-1 1, 1987

17. Namba RS, Kabo JM, Dorey FJ, Meals RA. Continuous passive motion versus immobilization. Clin Orthop. 1991;267:218222.

18. Frank C, Akeson WH, Woo SL-Y, Amiel D, Ing D, Coutts RD. Physiology and therapeutic value of passive joint motion. ClinOrthop. 1984;185:113-120.

19. Salter RB. The biological concept of continuous passive motion of synovial joints. The first eighteen years of basic research and its clinical implications. ClinOrthop. 1989; 242:12-24.

20. Basso DM, Knapp L: Comparison of two continuous passive motion protocols for patients with total knee implants. PhysTher 67(3):360-363, 1987
21. Colwell CW, Morris BA: The influence of continuous passive motion on the results of total knee arthroplasty. ClinOrthop 276:225228, 1992

22. Coutts RD: Continuous passive motion in the rehabilitation of the total knee patient, its role and effect. Orthop Rev 1 5(3):126-134, 1986. 